Revue

Revue de l'histoire des religions

de Ihistoire des religions

1 | 2014

Varia

\title{
Littérature et spiritualité au miroir de Henri
} Bremond

Textes réunis par Agnès Guiderdoni-Bruslé et François Trémolières, Grenoble, Jérôme Millon, 2011

\section{Stéphane-Marie Morgain}

\section{CpenEdition}

Journals

Édition électronique

URL : http://journals.openedition.org/rhr/8231

DOI : $10.4000 /$ rhr.8231

ISSN : 2105-2573

Éditeur

Armand Colin

Édition imprimée

Date de publication : 1 mars 2014

Pagination : 155-157

ISBN : 978-2200929107

ISSN : 0035-1423

Référence électronique

Stéphane-Marie Morgain, "Littérature et spiritualité au miroir de Henri Bremond ", Revue de l'histoire des religions [En ligne], 1 | 2014, mis en ligne le 13 mai 2014, consulté le 22 septembre 2020. URL :

http://journals.openedition.org/rhr/8231 ; DOI : https://doi.org/10.4000/rhr.8231

Ce document a été généré automatiquement le 22 septembre 2020

Tous droits réservés 


\section{Littérature et spiritualité au miroir de Henri Bremond}

Textes réunis par Agnès Guiderdoni-Bruslé et François Trémolières, Grenoble, Jérôme Millon, 2011

Stéphane-Marie Morgain

\section{RÉFÉRENCE}

Littérature et spiritualité au miroir de Henri Bremond, textes réunis par Agnès GuiderdoniBruslé et François Trémolières, Grenoble, Jérôme Millon, 2011, 22 cm, 218 p., $19 €$, ISBN 978-2-8413-7266-9.

1 La publication en 2006, sous la direction de François Trémolières, de l'Histoire littéraire du sentiment religieux en France depuis la fin des guerres de religion jusqu'à nos jours, aux Éditions Jérôme Millon, augmentée de nombreuses annexes (textes inédits, Introduction à la philosophie de la prière, index, table analytique, bibliographie bremondienne), a relancé l'intérêt scientifique pour l'œuvre d'Henri Bremond. Ces mêmes Éditions rendent compte de ce dynamisme par la parution régulière d'ouvrages collectifs, fruits d'études monographiques ou de journées d'étude. Notons-le : Henri Bremond histoire de la "faim de Dieu» (2006), recueil des contributions d'Émile Goichot qui, décédé en 2003, n'avait pu achever la nouvelle édition de l'Histoire littéraire du sentiment religieux. Ce volume rend hommage au grand spécialiste de Bremond, auteur d'une thèse marquante consacrée à Henri Bremond historien du sentiment religieux et offre aux lecteurs l'une des meilleures introductions à l'œuvre de l'ancien jésuite.

2 Le présent ouvrage, préparé d'après les journées d'études « La littérature du XVII ${ }^{\mathrm{e}}$ siècle au miroir de l'Histoire littéraire du sentiment religieux en France de Henri Bremond» tenues à la Faculté de philosophie, arts et lettres de l'Université catholique de Louvain les 30 et 31 mars 2009, est le prolongement de Histoire et littérature chez Henri Bremond (2009), qui réunissait, sous la direction d'Étienne Fouilloux et François Trémolières, les Actes de la journée d'étude tenue à la Bibliothèque municipale de Lyon le 4 juin 2008 . Il 
aborde le type d'écriture bremondienne entre l'histoire des historiens et celles des littéraires et la réception de l'opus dans les années 1920-1940, posant ainsi les jalons de multiples approfondissements des liens entre histoire et littérature, histoire et spiritualité.

Le rappel des ouvrages publiés chez Jérôme Millon montre la difficulté d'interprétation de l'œuvre d'Henri Bremond et la diversité des champs d'investigation ouverts aux chercheurs. Les références à Histoire et littérature mentionnées dans Littérature et spiritualité indiquent le lien entre les deux collectifs et la permanence de la pluridisciplinarité des approches historiques, littéraires, artistiques, toutes au service d'une lecture moderne de l'Histoire littéraire du sentiment religieux et d'une meilleure connaissance de son auteur. On regrette que la dimension théologique de l'œuvre bremondienne soit si rapidement dévalorisée, voire exclue (Augustin Laffay et Bernard Joassart), sans qu'une étude approfondie rende compte de cette affirmation. Un éclaircissement raisonné et documenté sur le rapport entre littérature et théologie aiderait à fonder ce bannissement et à en expliquer les motifs.

4 La partie plus historique de Littérature et spiritualité poursuit la réflexion antérieure sur la réception de l'Histoire littéraire dans différents contextes, que ce soit dans les Analecta Bollandiana, les revues historiques françaises et belges, ou les revues italiennes. Ces études de Bernard Joassart et Silvia Mostaccio sont éclairées par l'excellente présentation du dossier romain de l'Affaire Tyrrell (1909) par Augustin Laffay dont l'exploitation des sources inscrit l'ensemble de cette première partie dans le débat moderniste et l'encyclique Pascendi. François Trémolières verse à ce dossier déjà volumineux l'examen de la condamnation du Sainte Chantal de Bremond (1912), qui se situe dans la lignée de celle des modernismes littéraire, exégétique (d'Alfred Loisy) et historique (de Mgr Duchesne en 1913). La mise à l'Index du Sainte Chantal élargit celle de l'hagiographie des saints légendaires de l'Antiquité chrétienne à l'hagiographie en général qui est au cœur du projet bremondien (p.103-120). Cette première partie complète et poursuit très logiquement les contributions d'Histoire et littérature en replaçant la réception et la postérité méthodologique et idéologique du grand œuvre de Henri Bremond dans le contexte agité des réactions romaines.

5 La seconde partie s'interroge précisément sur ce statut de l'œuvre, mais aussi sur celui des textes lus, cités et analysés, ou encore des images (Pierre-Antoine Fabre, p. 155-175). Ici encore, les études se complètent les unes les autres, comme celle de Sophie Houdard (p.124-141), sur la réécriture des scènes à partir de textes lus, réinterprétés et transmis par Bremond. Cet ensemble de travaux met en lumière l'extrême richesse de l'Histoire littéraire du sentiment religieux en France et les nouvelles problématiques proposées par Henri Bremond. 